\title{
EXPERIMENTAL INVESTIGATION INTO THE SEISMIC FRAGILITY OF A COMMERCIAL GLAZING SYSTEM
}

\author{
Fransiscus A. Arifin ${ }^{1}$, Timothy J. Sullivan ${ }^{2}$ and \\ Rajesh P. Dhakal ${ }^{3}$
}

(Submitted November 2019; Reviewed March 2020; Accepted April 2020)

\begin{abstract}
Good seismic performance of glazing systems is essential to maintaining building functionality and limiting repair costs in a post-earthquake scenario. This paper reports on experimental research into the seismic performance of a standard commercial glazing system used in New Zealand. The focus of the research is to provide information not only on the life-safety performance of glazing but also on the serviceability of glazing systems, considering post-earthquake weather-tightness. This paper first describes the experimental testing set-up developed at the University of Canterbury to achieve this, then details the damage observed and finally, fragility functions for different damage states are reported. Leakage of the glazing is seen to initiate at a median storey drift demand of only $0.35 \%$, whereas glass breakage did not occur until a median drift storey demand of $5.0 \%$. The results obtained from this research demonstrate that the life-safety risk posed by modern commercial glazing in earthquakes will typically be low but the serviceability performance, and in particular weather-tightness post-earthquake, should be improved.
\end{abstract}

Keywords: Glazing, Fragility, Seismic Performance, Experimental

\section{INTRODUCTION}

Recent events, such as the 2016 Kaikoura earthquake and the 2010-2011 Canterbury earthquakes, have highlighted the damage earthquakes cause to glazing systems $[1,2]$. Figure 1 illustrates damage to glazing observed from the Canterbury earthquakes. Photos in the printed media [3] of shattered glass on footpaths and reports that areas may be cordoned off because of the risk posed by falling glass remind us that the performance of glass windows/glazing in earthquakes can be a life-safety matter. There were many reports of injuries due to broken glass lying in egress routes following the Canterbury earthquakes. In addition, the repair of glass facades can be costly and timeconsuming and accessibility to damaged parts can pose a significant challenge in many cases. Following the Kaikōura earthquake, it was claimed that glazing repairs in downtown Wellington cost as much as $\$ 50,000$ per pane [4].

Despite the apparent issues associated with poor performance of glazing in earthquakes, the New Zealand engineering community has a relatively limited amount of information available for the assessment of such risks. Research undertaken by BRANZ [5-7] provides useful insight into issues facing the seismic performance of glazing systems and details a testing procedure to evaluate the racking capacity of curtain wall glazing. However, the information provided in these reports has not translated into clear deformation limits or guidelines for engineers to assess the capacity of glazing systems for different performance/damage states. Section C10 of the MBIE guidelines for building seismic assessment [8] does identify that glazing may fall if there is damage to curtain wall framing systems, and yet expressions included in $\mathrm{C} 10$ for the drift capacity do not appear to have been rigorously verified. The life-safety drift limit provided stems from vague factors that are loosely based on empirical data from previous studies (e.g. [9]). For example, in the case of a modern curtain wall system, the life-safety drift limit is defined as four times the glass contact drift without clear definitions of what is included as a modern curtain wall system.

While life-safety has been considered in the guidelines, albeit still lacking, performance regarding serviceability is hardly taken into account. Serviceability performance measures such as water-tightness and air-tightness are important requirements for glazing, and the failure to maintain either of them may cause economic loss due to repairs and downtime. Unfortunately, this normally goes unnoticed; thereby giving people, who judge the performance purely based on visually distinguishable damage, a false sense of confidence that the traditional glazing performs well.

In light of the above, research into the seismic performance of commercial glazing systems has been proceeding at the University of Canterbury from 2018 to 2020 . The focus of this research is to investigate not only on the life-safety performance of glazing but also on the serviceability of glazing systems, considering post-earthquake weather-tightness. Note that although some studies have looked at the seismic performance of glazing/windows (e.g. [10]), they don't assess the weathertightness as the practical challenges to assess this aspect is daunting because it requires a lot of work and specific apparatus. This paper focusses on the experimental work done as a part of this project to establish the fragility of a commercial glazing system typical of New Zealand construction. Previous research [11] provide useful indications on the fragility of glazing systems, but the applicability of these fragility functions for the New Zealand building stock is questionable, as will be demonstrated in this research. This paper first describes the experimental testing set-up developed at the University of Canterbury. Note that, as a scope, the out-of-plane behaviour of the glazing system was not investigated. The paper then details the damage observed and finally, develops the fragility functions for different damage states based on the test results.

\footnotetext{
1 Corresponding Author, PhD Student, University of Canterbury, Christchurch, fransiscus.arifin@pg.canterbury.ac.nz

2 Professor, University of Canterbury, Christchurch, timothy.sullivan@ canterbury.ac.nz (Member)

3 Professor, University of Canterbury, Christchurch, rajesh.dhakal@canterbury.ac.nz (Fellow)
} 


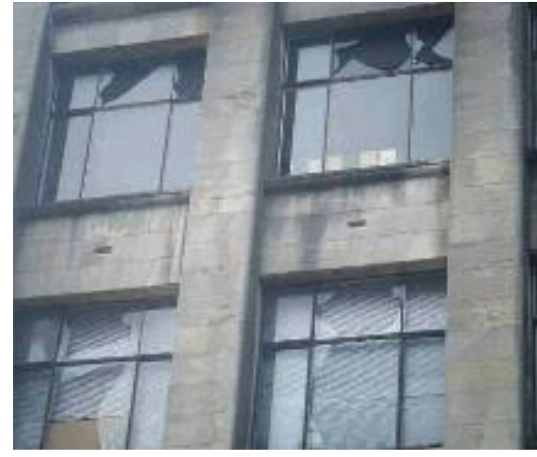

(a)
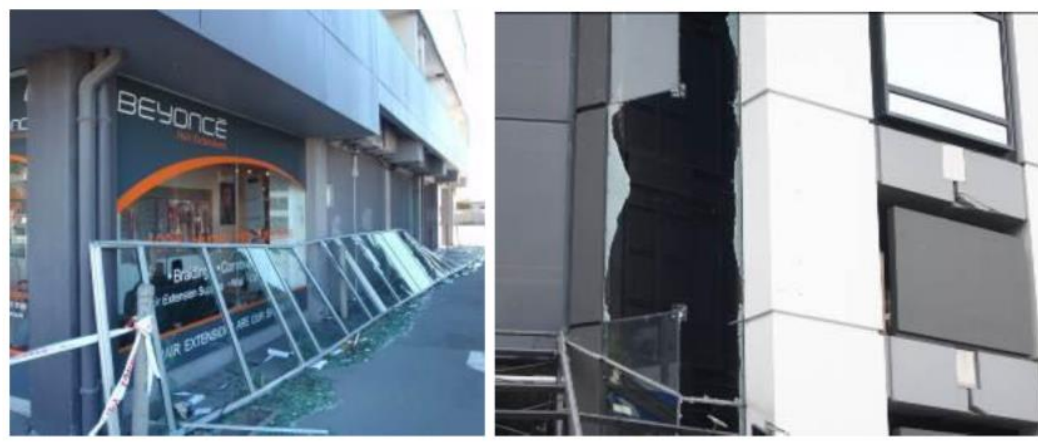

(b)

Figure 1: Examples of glazing damage that occurred in (a) the September 4th 2010 Darfield earthquake [1] and (b) the February 22nd 2011 Christchurch earthquake [2].

\section{EXPERIMENTAL TESTING}

A traditional experimental test into the behaviour of a driftsensitive non-structural component would utilise quasi-static cyclic testing in which lateral drift demands are incrementally imposed on an element and the development of different damage states is observed. However, the main objectives of experimental testing in this project were to assess both the serviceability and the ultimate limit state performance of glazing units. As such, to investigate the serviceability performance of glazing, it was recognised that any experimental testing should also include a test of weather-tightness in postearthquake conditions. To this extent, New Zealand standard NZS4284: Testing of building facades (2008) [12] specifies a range of testing protocols, including a seismic test protocol that requires a cyclic water penetration test after a specified lateral drift demand has been imposed. The testing protocol in NZS4284 also requires the drifts to be imposed at high velocity, but after consulting with the industry, it was decided that the testing in this research would utilise quasi-static cyclic testing and cyclic water penetration tests with controlled air pressure. Whilst testing at high-velocity could affect the performance of some sealants, the glazing examined in this research possessed low-rise PVC glazing wedge (gaskets) that are not expected to be velocity dependent and hence, the quasi-static testing approach was deemed appropriate. Furthermore, testing for airtightness requires specific apparatus which proved to be difficult to procure. As such, due to the possibility of relating weather-tightness (air and water-tightness) to water-tightness [13], only water-tightness will be observed in this experiment.

Figures 2 to 4 illustrate the experimental set-up adopted for the testing. The glazing was erected between two concrete slabs, representing two different floors of a building with a storey height of $3.6 \mathrm{~m}$. The weight of the slabs was carried by steel frames at either end, designed to permit translation of the top slab in the longitudinal direction and prevent translation in the orthogonal direction. A hydraulic actuator capable of imposing $800 \mathrm{kN}$ force was fixed between the top slab and a steel reaction frame (see Figures 2 and 3 ). Steel posts were flanked either side of the glazing specimen; thereby fitting full scale one-storey glazing specimens $2.976 \mathrm{~m}$ long by $3.385 \mathrm{~m}$ high (when the glazing was built up to underside of the concrete slab). A timber water-box was designed and erected to support four spray nozzles, spaced $1800 \mathrm{~mm}$ apart as seen in Figure 4 and approximately $900 \mathrm{~mm}$ away from the glass specimen (in line with the recommendations in NZS4211: Specification for performance of windows (2008) [14]). Figure 4 also shows a water tank from which water was pumped at a controlled flowrate through piping to the four nozzles inside the waterbox. The system was designed such that the water applied to the specimen would drain to a sump and be pumped back to the water tank for recirculation as part of the test.

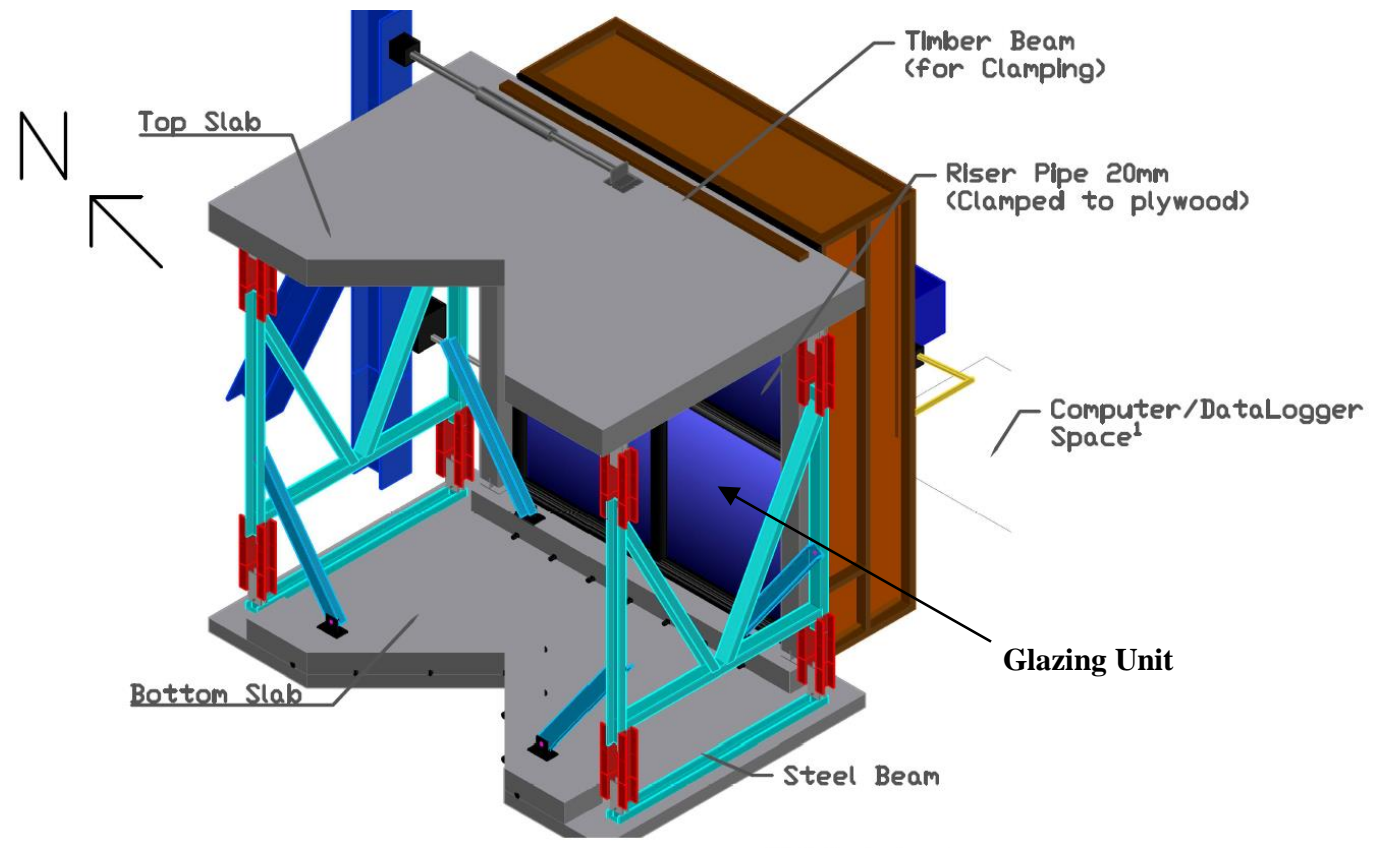

Figure 2: Experimental set-up for testing of glazing systems in commercial buildings; showing concrete slabs, support frames, water-box and glazing specimen. 


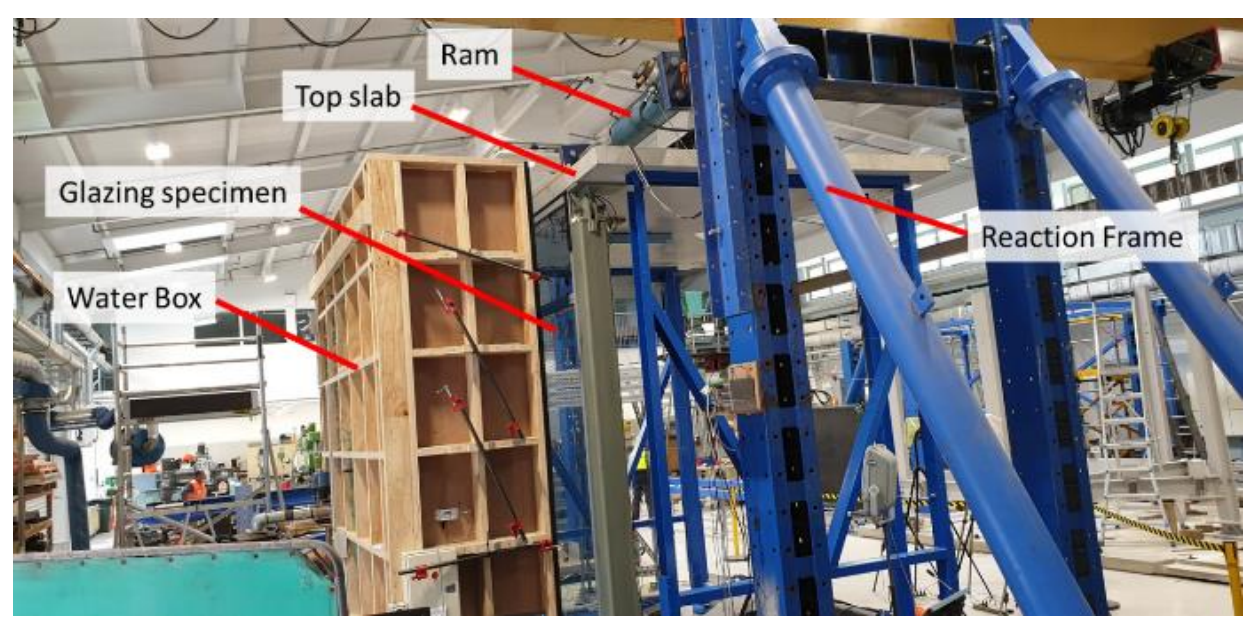

Figure 3: Photo of overall experimental set-up realised in the laboratory.
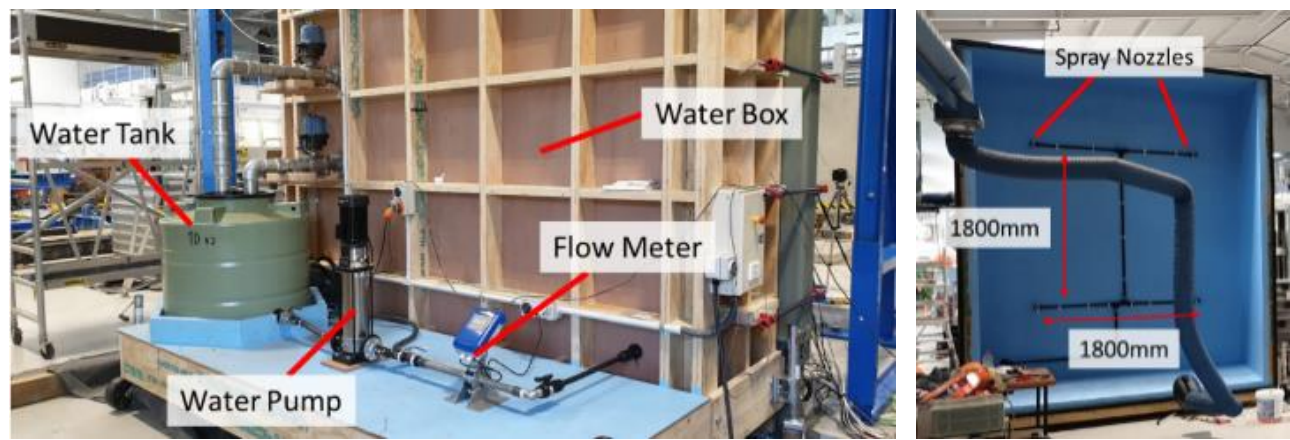

Figure 4: Equipment required for water-tightness test. View from rear (left) and view of spray nozzle locations inside box (right).
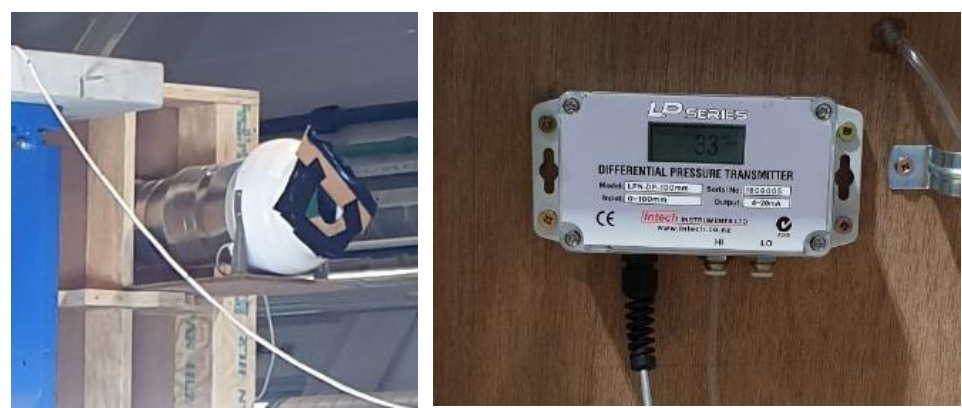

Figure 5: Air pressure control unit. Air blower (left) and differential pressure sensor (right).

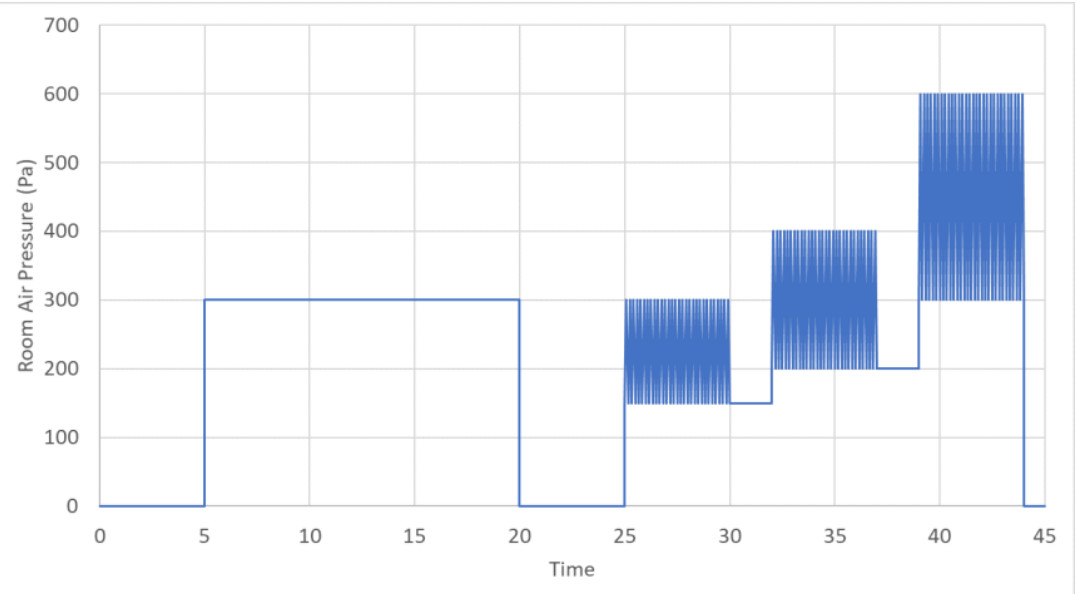

Figure 6: Differential air pressure imposed on glazing unit during water testing in line with NZS4284.

The system also included an air blower and air pressure transducers measuring interior and exterior air pressures to permit controlled air pressure to be applied during water testing, in line with NZS4284 recommendations, shown in Figure 5.
Figure 6 shows the differential air pressure distribution applied during a water test. The figure shows that whilst spraying the specimen with water, the air pressure is initially held at $300 \mathrm{~Pa}$ for 15 minutes and subsequently, a series of cyclic pressure 
phases are run over 5-minute periods with a maximum air pressure of $600 \mathrm{~Pa}$ imposed.

The curtain wall glazing specimens examined in this work are a standard type of commercial glazing unit commonly found in New Zealand. The glazing, shown in Figure 7, included two tall glass panes $1.426 \mathrm{~m}$ wide by $2.56 \mathrm{~m}$ tall over the lower part of the façade and two smaller glass panes $1.426 \mathrm{~m}$ wide by $0.662 \mathrm{~m}$ tall in the top part. The aluminium framing included a $16 \mathrm{~mm}$ clearance between the glass edges and the framing, with lowrise PVC wedges (gaskets) rolled into position to provide a water seal. The outer edges of the framing were screwed into the steel posts either side of the glazing, the concrete slab at the top and a concrete upstand at the bottom.

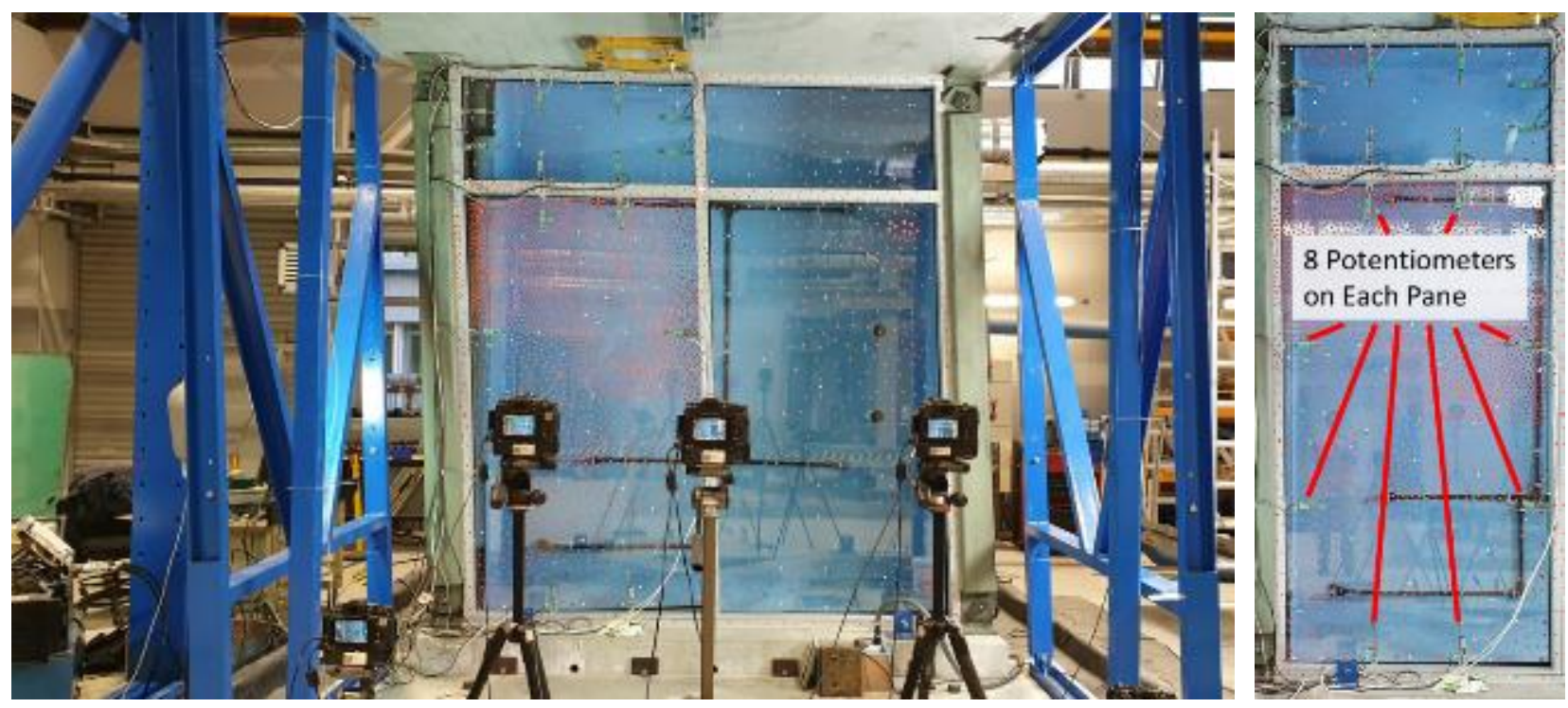

Figure 7: Photo showing glazing specimen and instrumentation used in the experimental testing, showing cameras and red dots used for particle-tracking (left) and potentiometers used to monitor displacements of panes relative to framing (right).

The instrumentation used in the testing included a load cell in the actuator measuring the applied force, as well as displacement transducers measuring the in-plane and out-ofplane displacements of the top slab. Furthermore, as shown in Figure 7, particle tracking was used to monitor the in-plane movements of the framing and glass, with a number of potentiometers also used to measure the displacements of the glass panes relative to the framing.

Lateral displacements were imposed on the specimen following the FEMA 461: Interim Testing Protocols for Determining the Seismic Performance Characteristics of Structural and Nonstructural Components (2007) [15] loading protocol with a target storey drift of $3.0 \%$. This implied that (following an initial water test) the seismic testing started with a peak storey drift demand of $0.15 \%$ and this was then incremented by a factor of 1.4 up until the attainment of a $3.0 \%$ drift demand (the intermediate drift levels being $0.2 \%, 0.28 \%, 0.4 \%, 0.56 \%$, $0.78 \%, 1.1 \%, 1.5 \%$ and $2.1 \%$ ). Testing was continued beyond $3.0 \%$ storey drift in steps of $0.9 \%$ drift (in line with FEMA 461) until glazing failure. Two cycles of demand (positive and negative) were imposed at each drift level and then the frame was re-centered. After re-centering, static and cyclic water penetration tests were conducted according to NZS4284. If no leakage was observed then the water penetration tests were also conducted after the next increment of drift demand. Once leakage was observed and recorded, subsequent increments in drift demand did not include water testing.

\section{RESULTS OF THE EXPERIMENTAL TESTING}

The testing provided good insight into the vulnerability of glazing systems, both from the serviceability and ultimate limit state perspectives. Three damage states (DSs) were recorded during the testing:

- DS1: loss of the water-tightness of glazing units, judged to occur when water first appeared on the inside face of the glazing.

- DS2: visual gasket failure in which gaskets were seen to have moved out of place (either jammed into framing or falling out) and would have prompted repair.

- DS3: failure of the glass (either significant cracking or fallout).

A summary of the results obtained in the three experimental tests is reported in Table 1. In addition to these global results, it was observed that damage was initially seen in the larger panes (refer Figure 7). The panes were observed to slide and rotate prior to locking up within the framing and hence the total drift capacity for DS3 was very large, at around 5\%. On the contrary, loss of water-tightness occurred at drifts as low as $0.15 \%$, with the median drift capacity being $0.35 \%$.

Table 1: Experimental results, arranged according to observe damage states, from testing of glazing systems at UC.

\begin{tabular}{|c|c|c|c|c|c|c|c|}
\hline \multirow{2}{*}{ Specimen } & \multirow{2}{*}{ Date } & \multicolumn{2}{|c|}{ DS1 - Water leakage } & \multicolumn{2}{|c|}{ DS2 - Gasket failure } & \multicolumn{2}{|c|}{ DS3 - Glass/frame failure } \\
\hline & & Drift (\%) & Force $(\mathbf{k N})$ & Drift (\%) & Force $(k N)$ & Drift (\%) & Force (kN) \\
\hline 1 & Oct $4^{\text {th }}, 2019$ & 0.15 & 1.2 & 2.1 & 2.2 & 4.8 & 8.4 \\
\hline 2 & Oct $17^{\text {th }}, 2019$ & 0.7 & 1.3 & 3.0 & 1.4 & 4.5 & 7.7 \\
\hline 3 & Oct $29^{\text {th }}, 2019$ & 0.4 & 1.8 & 3.0 & 2.5 & 5.7 & 10.0 \\
\hline
\end{tabular}


Table 2: Damage states observed for glazing systems tested experimentally at $U C$ and associated fragility parameters.

\begin{tabular}{|c|c|c|c|}
\hline \multirow[b]{2}{*}{$\begin{array}{l}\text { Damage } \\
\text { State }\end{array}$} & \multirow[b]{2}{*}{ Description } & \multicolumn{2}{|c|}{ Fragility Parameters } \\
\hline & & $\begin{array}{c}\text { Median Drift Capacity } \\
\left(x_{m}\right)\end{array}$ & $\begin{array}{c}\text { Dispersion } \\
(\beta)\end{array}$ \\
\hline DS1 & Water leakage & $0.35 \%$ & 0.78 \\
\hline DS2 & Gasket failure & $2.66 \%$ & 0.21 \\
\hline DS3 & Glass/frame failure & $4.98 \%$ & 0.12 \\
\hline
\end{tabular}

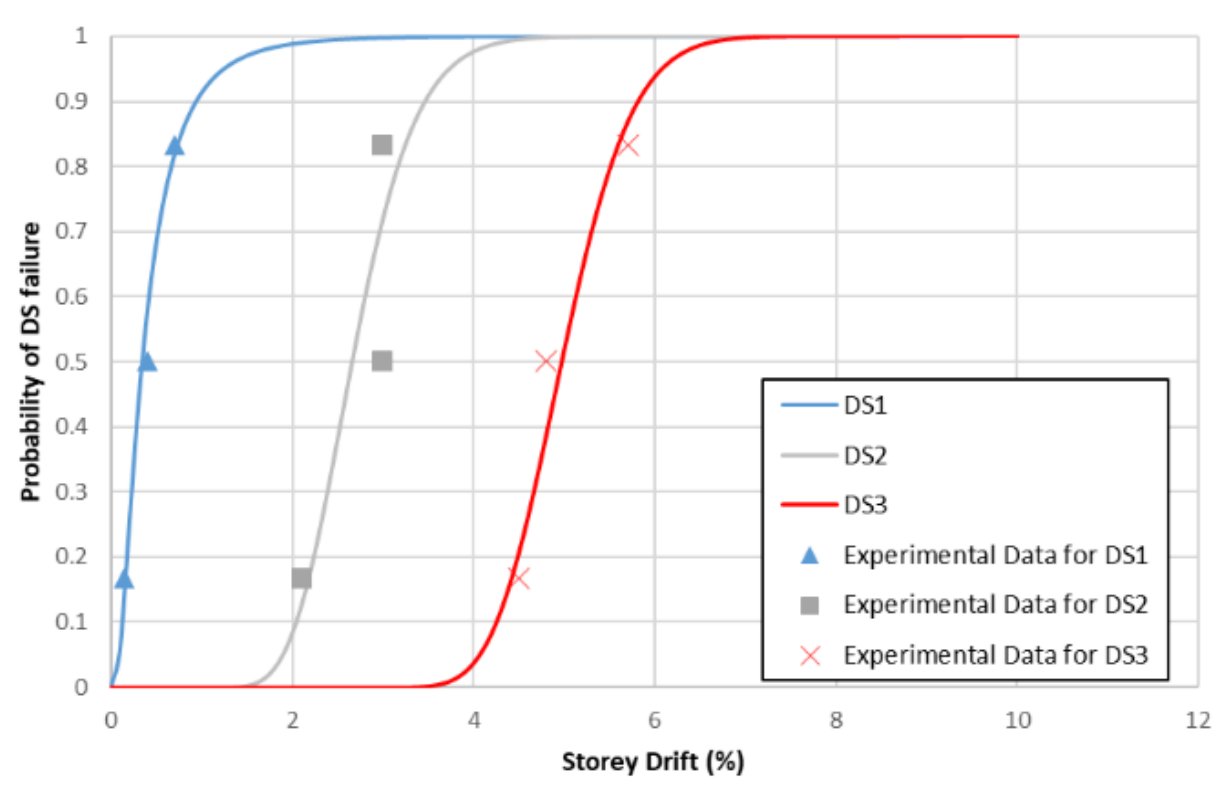

Figure 8: Fragility functions for commercial glazing, obtained from experimental tests results.

To establish fragility curves, a log-normal distribution was assumed and regression analyses were conducted to identify the median and dispersion for each damage state in line with recommendations of Porter et al. [16]. The resulting fragility parameters, together with a description of the three damage states investigated, are presented in Table 2 and plotted in Figure 8. These results shown in Figure 8 define the fragility for different damage states via Equation 1.

$P_{i}(D)=\Phi\left(\frac{\ln \left(\frac{D}{\overline{\bar{x}}_{D S i}}\right)}{\beta_{D S i}}\right)$

where $P_{i}(D)$ indicates the conditional probability that the glazing system will experience damage corresponding to damage state "DSi" or worse when the demand is $D, \Phi$ represents the standard normal cumulative distribution function, $D$ is the variable demand parameter (e.g. drift), $x_{i}$ is the median value of the test results, $\beta_{i}$ is the dispersion (logarithmic standard deviation) of the test results, and subscript " $i$ " represents the damage state of interest (e.g. $i=1$ signifies DS1).

\section{COMPARISON OF FRAGILITY RESULTS WITH CURVES IN THE LITERATURE}

As mentioned earlier, O'Brien et al. [11] provide indications on the fragility of glazing systems that could be considered typical of construction practice in North America. Interestingly, the median drift capacity for glass cracking was significantly smaller for the majority of the specimens tested, with cracking occurring at drifts between $1 \%$ and $3 \%$. Furthermore, damage to the gaskets tended to occur at a similar drift as glass cracking. Some difference can be anticipated owing to different specimen sizes and spacing around edges. Nevertheless, the results of O'Brien et al. [11], which were also used by Khakurel et al. [17] to develop seismic loss contribution functions of glazing systems, suggest much larger drift capacity for the serviceability limit state than the glazing systems tested in this research. That said, the testing conducted by O'Brien et al. [11] did not include tests of water-tightness and hence, one could argue that their serviceability limit state is more similar to the DS2 state examined herein, which did have a median drift capacity of $2.66 \%$ and thus can be considered similar to previous results.

In the context of building assessment through a performancebased earthquake engineering framework such as that provided in FEMA P-58: Seismic Performance Assessment of Buildings (2012) [18], it is also relevant to consider how the fragility values observed in this work compare to the fragility of other common building components. As reported by Mosqueda [19] and Yeow et al. [20], one of the most fragile building components used in both North America and New Zealand are non-structural plasterboard partition walls, which exhibit first signs of damage (cracking) at median drift demands of around $0.3 \%$ to $0.6 \%$ [21]. Thus, given that the glazing tested in this research was observed to lose water-tightness at drifts of $0.3 \%$, it is apparent that glazing fragility could significantly affect the serviceability performance of a building, being one of the most critical building components. However, in noting this, two points should be considered: (i) the results reported in this work are for a single glazing system and although it is a commonly used glazing system in New Zealand, a range of systems are available in practice and owing to different detailing practices, such systems could well be characterised by larger drift capacities; (ii) the exceedance of DS1 was only observed through water testing and if one relies on visual inspection only, then the glazing system would not be identified as being damaged in until drifts corresponding to DS2 and hence the repair actions would be considerably reduced (at least in the short term). 


\section{CONCLUSIONS}

This paper has reported on research undertaken at the University of Canterbury into the seismic performance of glazing systems. The focus of the research has been to provide information not only on the life-safety performance of glazing but also on the serviceability of glazing systems, considering post-earthquake water-tightness. The paper first described the experimental test set-up developed to undertake quasi-static cyclic testing with alternating water-tightness tests under a controlled air-pressure differential. The results, in terms of drift capacity at key damage states are then reported. Leakage of the glazing was seen to initiate at a median storey drift demand of only $0.35 \%$, whereas glass breakage did not occur until a median drift storey demand of $5.0 \%$. The results obtained from this research demonstrate that the life-safety risk posed by modern commercial glazing in earthquakes will typically be low but the serviceability performance, and in particular watertightness post-earthquake, should be improved as part of future research.

Despite the poor serviceability performance of the glazing system tested, it should also be recognised that the results reported in this paper are for a single glazing system. Although the system is thought to be typical of the New Zealand construction industry, a range of systems are available in practice and owing to different detailing practices, such systems could be characterised by larger drift capacities. In addition, the loss of water-tightness was only observed through water testing and if visual inspection is relied on in a post-earthquake scenario, the perceived levels of damage in moderate earthquakes would be much less extensive than those suggested by these test results.

\section{REFERENCES}

1 Dhakal RP (2010). "Damage to Non-Structural Components and Contents in 2010 Darfield Earthquake". Bulletin of the New Zealand Society of Earthquake Engineering, 43(4): 404-411. https://doi.org/10.5459/bnzsee.43.4.404-411

2 Baird A, Palermo A and Pampanin S (2011). "Façade damage assessment of multi-storey buildings in the 2011 Christchurch earthquake". Bulletin of the New Zealand Society of Earthquake Engineering, 44(4): 368-376. https://doi.org/10.5459/bnzsee.44.4.368-376.

3 Stuff (2017). Earthquake: Deaths, major damage after severe 7.5 quake hits Hanmer Springs, tsunami warning issued. http://www.stuff.co.nz (Accessed 14/10/2019)

4 Valli A (2017). "Record of Discussion from Meeting at University of Canterbury". University of Canterbury, June 2017.

5 Thurston SJ and King AB (1992). "Two-Directional Cyclic Racking of Corner Curtain Wall Glazing”. BRANZ Study Report No. 44, BRANZ Ltd, Judgeford, New Zealand.

6 Lim KYS and King AB (1991). "The Behaviour of External Glazing Systems under Seismic In-Plane Racking". BRANZ Study Report No. 39, BRANZ Ltd, Judgeford, New Zealand.

7 Wright PD (1989). "The Development of a Procedure and Rig for Testing the Racking Resistance of Curtain Wall Glazing". BRANZ Study Report No. 17, BRANZ Ltd, Judgeford, New Zealand.
8 MBIE (2017). "The Seismic Assessment of Existing Buildings: Technical Guidelines for Engineering Assessments". Initial Release, Ministry of Business, Innovation and Employment, New Zealand.

9 Behr RA (2009). "Architectural Glass to Resist Seismic and Extreme Climatic Events". $1^{\text {st }}$ Edition, Woodhead Publishing, Cambridge, UK, 259pp.

10 Carradine DN, Kumar A, Fairclough R and Beattie G (2020). "Serviceability fragility functions for New Zealand residential windows". Bulletin of the New Zealand Society for Earthquake Engineering, 53(3): 137-143. https://doi.org/10.5459/bnzsee.53.3.137-143

11 O'Brien WC, Memari AM, Kremer PA and Behr RA (2012). "Fragility curves for architectural glass in stickbuilt glazing systems". Earthquake Spectra, 28(2): 639665. https://doi.org/10.1193/1.4000011

12 SNZ (2008). "NZS4284:2008: Testing of Building Facades". Standards New Zealand, Wellington, 36pp.

13 Van Den Bossche N and Janssens A (2016). "Air-tightness and water-tightness of window frames: Comparison of performance and requirements". Building and Environment, 110: 129-139. https://doi.org/10.1016/j.buildenv.2016.09.034

14 SNZ (2008). "NZS4211:2008: Specification for Performance of Windows". Standards New Zealand, Wellington, 26pp.

15 FEMA (2007). "FEMA461: Interim Testing Protocols for Determining the Seismic Performance Characteristics of Structural and Nonstructural Components". Federal Emergency Management Agency, Washington, DC, USA, $113 p p$.

16 Porter KA, Kennedy R and Bachman R (2007) "Creating fragility functions for performance based earthquake engineering". Earthquake Spectra, 23(2): 471-489. https://doi.org/10.1193/1.2720892

17 Khakurel S, Yeow TZ, Chen F, Wang Z, Saha SK and Dhakal RP (2019). "Development of cladding contribution functions for seismic loss estimation". Bulletin of the New Zealand Society for Earthquake Engineering, 52(1): 23-43. https://doi.org/10.5459/bnzsee.52.1.23-43

18 FEMA (2012). "FEMA P-58.1: Seismic Performance Assessment of Buildings Volume 1-Methodology". Federal Emergency Management Agency, Washington, DC, USA, 340pp.

19 Mosqueda G (2016). "Interior Cold-Framed Steel Framed Gypsum Partition Walls". Background Document FEMA P-58/BD-3.9.32, Applied Technology Council, Redwood City, CA, 19pp.

20 Yeow TZ, Sullivan TJ and Elwood KJ (2018). "Evaluation of fragility functions with potential relevance for use in New Zealand". Bulletin of the New Zealand Society for Earthquake Engineering, 51(3): 127-144. https://doi.org/10.5459/bnzsee.51.3.127-144

21 Dhakal RP, Pourali A and Saha SK (2016). "Simplified Seismic Loss Functions for Suspended Ceilings and Drywall Partitions". Bulletin of the New Zealand Society for Earthquake Engineering, 49(1): 64-78. https://doi.org/10.5459/bnzsee.49.1.64-78 